\title{
Neuroadaptaciones en los sistemas Glutamatérgico y Dopaminérgico durante la abstinencia de la cocaína ${ }^{1}$
}

\author{
Crespo, J.A.; Martín, S.; Ambrosio, E. \\ Universidad Nacional de educación a distancia (UNED). Ciudad Universitaria. 28040 Madrid.
}

Enviar correspondencia a:

Emilio Ambrosio: Departamento de Psicología. Universidad Nacional de Educación a Distancia (UNED). Ciudad Universitaria. 28040 Madrid. Fax: 9139862 87. Correo electrónico: eambrosio@psi.uned.es

\section{RESUMEN}

El fenómeno de las recaídas en la adicción a drogas tras un periodo de abstinencia mantenido sigue siendo uno de los retos más difíciles de resolver. La vuelta al consumo produce, entre otros efectos, un gran desconcierto en el ex-abstinente y desorientación y desmotivación en los profesionales y el entorno familiar. Los factores que pueden facilitar un proceso de recaída son múltiples pero, en general, se incluyen en dos grandes grupos: los exógenos (fácil acceso a la sustancia; pertenencia a determinados grupos sociales...etc) y los endógenos (disfunciones de sistemas de neurotransmisores; condicionamiento a estímulos externos, la personalidad del sujeto; el estado mental...etc). Siendo obvia la importancia de los factores exógenos, hay cada día mayor cantidad de trabajos en la literatura científica que resaltan la posible función de los factores endógenos. En este trabajo presentaremos datos que demuestran la existencia de neuroadapataciones en los sistemas glutamatérgico y dopaminérgico tras la extinción de la conducta de autoadministración de cocaína en diversas regiones cerebrales de roedores de laboratorio. Esas neuroadaptaciones son más permanentes y duraderas en el sistema dopaminérgico. Considerados globalmente, estos resultados sugieren que durante la abstinencia de psicoestimulantes pueden producirse neuroadaptaciones en distintos sistemas de neurotransmisores que pueden mantener el deseo por la droga, exacerbar la potencialidad de los estímulos condicionados, incrementar la ansiedad...etc, y favorecer, en definitiva, una mayor vulnerabilidad a la recaída.

Palabras clave: autoadministración, extinción, cocaína, glutamato, dopamina, receptores, neuroadaptaciones, drogadicción, recaída.

\section{INTRODUCCION}

$\mathbf{L}$ a cocaína sigue siendo una droga de abuso con alta prevalencia en las sociedades occidentales. Aunque los efectos de esta droga se ejercen sobre diversos sistemas de neurotransmisores, uno de los más importantes parece ser el dopaminérgico, especialmente en su porción mesocorticolímbica.

\section{SUMMARY}

There are different factors that could participate in relapse to drug addiction. These factors are characterized as exogenous and endogenous. It is clear that exogenous factors such as peer groups, poor socioeconomical level...etc, are relevant to induce relapse in drug addiction. However, the role of endogenous factors such as disregulation of neurotransmitter systems, subject's personality....etc, are less understood. In this work we present data that suggest that, after extinction of cocaine self-administration in rats, there are neuroadaptative changes in dopaminergic and glutamatergic brain receptors in cerebral areas involved in cocaine reinforcing effects. These neuroadaptations are more permanent and long lasting in dopaminergic receptors compared to glutamatergic receptors. The results of this study suggest that specific neuroadaptative changes in glutamatergic and dopaminergic receptor systems might be involved in negative states of cocaine withdrawal and facilitate vulnerability to cocaine relapse.

Key words: self-administration behavior; extinction behavior; cocaine; glutamate; dopamine; receptors; neuroadaptative changes; drug abuse; relapse.

1Trabajo ganador del Premio Zambón-Socidrogalcohol en su edición 2000.

Numerosos datos en la literatura implican al sistema mesocorticolímbico dopaminérgico en las acciones reforzantes de la cocaína y, posiblemente, en la dependencia de esta droga (Woolverton et al.,1992).

El principal efecto farmacológico de la cocaína es inhibir la recaptación de dopamina, noradrenalina y serotonina. En sujetos no modificados genéticamen- 
te, parece ser que los efectos reforzantes positivos de la cocaína están ligados sobre todo a su acción sobre la recaptación de dopamina. No obstante, recientemente se ha descrito que en ratones transgénicos desprovistos del transportador de dopamina, la función de la serotonina en las acciones reforzantes positivas de la cocaína puede ser relevante (Rocha et al., 1999). Dada la probable función preponderante de la dopamina en sujetos normales y el efecto inhibidor de la cocaína sobre la recaptación de este neurotransmisor, el resultado neto de las acciones farmacológicas de esta droga es que hay un incremento en la disponibilidad extracelular de dopamina, para actuar sobre sus receptores presinápticos y postsinápticos. En consecuencia, es lógico pensar que en las manifestaciones comportamentales de la cocaína pueden estar implicados los receptores dopaminérgicos, ya sea en su número o en su función. Aunque se ha estudiado si el tratamiento crónico de cocaína cambia la densidad de receptores dopaminérgicos y/o su función, en la literatura científica hay resultados contradictorios. Así, se ha descrito que la administración repetida de cocaína aumenta la densidad de los receptores D1 dopaminérgicos cerebrales inmediatamente después de 15 días de tratamiento, y disminuye la densidad de esos receptores a los 14 días de la finalización del tratamiento (Kleven et al, 1990). Sin embargo, otros investigadores no han encontrados cambios en la densidad de receptores D1 dopaminérgicos a los 7 días de la finalización de un tratamiento de 6 días (Mayfield et al.,1992), o a 1 día después de un tratamiento de 8 días (Peris et al, 1990) o de 7 días de tratamiento (Kunko et al., 1997). De los estudios funcionales también se han obtenido resultados variables. Por ejemplo, algunos autores no han encontrado cambios en la regulación de la actividad de la enzima adenilato ciclasa asociada al receptor D1 dopaminérgico en los núcleos caudado putamen y accumbens después de la retirada de la droga una vez finalizado un tratameinto de 6 días (Mayfiled et al., 1992). No obstante, otros investigadores han demostrado que se produce un aumento de la inhibición del disparo de neuronas dopaminérgicas, tras la aplicación de agonistas de los receptores D1 dopaminérgicos en regiones mesolímicas, después de 2 semanas de tratamiento con cocaína, y que este efecto perdura durante al menos 1 mes desde la finalización del tratamiento (Henry y White, 1991; como es sabido, uno de los efectos fisiológicos de la cocaína es producir una disminución de la frecuencia basal de disparos en neuronas dopaminérgicas mesolímbicas).

En lo que respecta a los receptores del subtipo D2 dopaminérgicos, hay también resultados que no van en la misma dirección. Así, no se han encontrado cambios ni en la densidad de receptores ni en los niveles de ARNm del núcleo caudado putamen a los 7 días de retirada de un tratamiento con $40 \mathrm{mg} / \mathrm{Kg}$ de cocaína de 14 días, ya fuera la forma de administración intermitente o de infusión contínua (King et al., 1994). Sin embargo, se ha descrito que la administración diaria de una dosis de $10 \mathrm{mg} / \mathrm{Kg}$ durante 15 días produjo una disminución de los receptores D2 dopaminérgicos en el núcleo caudado putamen y un aumento en el accumbens (Goeders y Kuhar, 1987). Por otro lado, aunque en algunos trabajos no se hayan encontrado cambios en la densidad de receptores D2 dopaminérgicos sí parece que la función de estos receptores aumenta tras la infusión contínua, aunque no tras una administración intermitente ( Chen y Reith, 1993; Gifford y Johnson, 1992; King et al., 1994).

En relación con los resultados contradictorios comentados sobre los receptores dopaminérgicos, es importante destacar que en todos estos estudios hay apreciables diferencias en la duración del tratamiento, la dosis de cocaína administrada y el tiempo transcurrido desde que se administró la última dosis y el momento del sacrificio del animal. En todos los casos, además, la forma de administración de la droga fué pasiva y no se tuvo en cuenta el comportamiento del animal. En nuestros experimentos, por el contrario, hemos empleado el modelo de autoadministración intravenosa (el mejor modelo animal para el estudio de la drogadicción humana; ver Griffith et al., 1980 y Henningfield et al., 1992) porque está demostrado que cuando el sujeto regula su comportamiento (administración contingente) en presencia de diferentes reforzadores, sean o no drogas, aparecen diferencias significativas de tipo neurobiológico, comparadas con la administración pasiva (no contingente) de los mismos reforzadores. Por la dificultad del procedimiento y el enorme tiempo que conlleva la obtención de resultados con la metodología de la autoadminsitarción intravenosa, la mayoría de las investigaciones sobre los efectos neurobiológicos de la cocaína se han realizado con administraciones pasivas a intervalos de diferentes períodos de tiempo. A nuestro juicio, parte de las discrepancias en los datos obtenidos sobre los efectos de la cocaína y su retirada en la regulación de los receptores de dopamina, se deben a la no utilización de un modelo animal adecuado y a la no consideración de que el sujeto, además de sentir los efectos farmacológicos de la droga, tiene un comportamiento que puede incluso afectar a los efectos farmacológicos de la misma.

En lo que hace referencia a la participación de elementos neuronales del sistema glutamatérgico en los efectos de la cocaína, se ha demostrado que la activación de los receptores de glutamato favorece el desarrollo de la sensibilización locomotora a los estimulantes. El fenómeno de la sensibilización parece estar implicado en la inducción de psicosis paranoides provocadas por el consumo de psicoestimulantes y en las recaídas en la drogadicción (Kalivas et al., 1993). Así, se ha visto que el bloqueo de los receptores de 
glutamato del subtipo de NMDA impide el desarrollo de la sensibilización a cocaína (Karler et al., 1990; Wolf y Khansa, 1991), mientras que el bloqueo del subtipo AMPA impide, además, la expresión de la sensibilización (Karler et al., 1991). Datos recientes (Pierce et al., 1996) han implicado a la transmisión glutamatérgica en el núcleo accumbens en la expresión de la sensibilización. Dicha inervación glutamatérgica en el núcleo accumbens proviene de regiones como el subiculum, la amígdala, la corteza y el tálamo (Christie et al., 1987; Fuller et al., 1987). Pierce et al. (1996) comprobaron, además, que existen diferencias individuales en la expresión de la sensibilización conductual tras la administración de cocaína y que una de las posibles variables puede ser una diferente neurotransmisión glutamatérgica. Por otro lado, muchos estudios han demostrado que el desarrollo y expresión de la sensibilización conductual está asociado con un aumento de la liberación extracelular de dopamina en el núcleo accumbens. En la mediación de esta liberación de dopamina intervienen proyecciones glutamatérgicas desde la corteza prefrontal, dopaminérgicas desde el área ventral tegmental y serotoninérgicas desde los núcleos del rafe (Kalivas, 1995). En estudios de autoadministración, se ha comprobado que el pretratamiento con el antagonista de los receptores de NMDA dizocilpina( o MK-801) afecta a los patrones de adquisición de cocaína en animales pretratados con anfetamina (Schenk et al., 1993 a y b). Sin embargo, empleando programas de razón progresiva, la administración previa de MK-801 puede potenciar o atenuar en función de la dosis, las propiedades reforzantes de cocaína medidas en el modelo de autoadministración intravenosa (Ranaldi et al., 1996). Estos datos indican que puede haber una interacción entre los receptores de glutamato del subtipo de NMDA y la dependencia de cocaína aunque no está clara la dirección de esa interacción.

Por otra parte, recientemente se ha comprobado que la administración intracerebral de AMPA en el núcleo accumbens aumenta los efectos reforzantes de la cocaína. Además, la administración de AMPA en el núcleo accumbens una semana después de la retirada de cocaína reinstaura el comportamiento de autoadministración de esta droga por mecanismos que parecen ser independientes de la liberación de dopamina (Cornish et al.,1999). Estos resultados sugieren que un posible factor interviniente en las recaídas del consumo de cocaína puede ser el aumento de la transmisión glutamatérgica, además del ya conocido aumento de la transmisión dopaminérgica como elemento favorecedor de las recaídas. No obstante, otros autores han demostrado que un aumento de la transmisión glutamatérgica en el núcleo accumbens a través de los receptores metabotrópicos del glutamato (mGluRs) del grupo 3 (activados por agonistas como el AP4) no favorece las recaídas en la auto- administración de cocaína, es decir, es un factor protector (Vorel et al., 1999). Por otro lado, a diferencia de lo hallado por Cornish et al.(1999), si se induce experimentalmente una regulación a la alta de la subunidad GluR1 de los receptores AMPA, mediante una sobreexpresión de dicha subunidad por la administración directa en el núcleo accumbens de genes que codifican esa proteína, los efectos reforzantes de la cocaína en el paradigma del condicionamiento preferencial al sitio disminuyen (Carlezon et al.1999), y disminuye también la probabilidad de recaídas en la autoadministración de esa droga tras la extinción de ese comportamiento (Schmidt et al.,1999). Por tanto, los efectos del glutamato tras la extinción de la conducta de autoadministración de esta droga son complejos y también hay datos a favor y en contra de la implicación de la transmisión glutamatérgica en la facilitación de las recaídas a la cocainomanía.

Dado el estado actual de conocimientos en este campo que hemos expuesto hasta aquí, que hay interacciones entre los sistemas dopaminérgico y glutamatérgico (la dopamina libera glutamato y el glutamato libera dopamina), y la importancia del glutamato en fenómenos de condicionamiento (como ocurre en la drogadicción), en el trabajo que presentamos a continuación hemos estudiado si se producen neuroadaptaciones en ambos sistemas de neurotransmisores tras la extinción de la conducta de autoadministración de cocaína en roedores de laboratorio. El objetivo esencial de este estudio ha sido conocer más acerca de posibles factores de tipo endógeno que pueden participar en las recaídas en la addición a la cocaína. Nuestro abordaje es preclínico, combinando metodologías comportamentales y neurobiológicas, porque pensamos que solamente con aproximaciones experimentales que tienen en cuenta conjuntamente enfoques neurobiológicos y comportamentales es posible avanzar en el conocimiento de los procesos básicos que operan en esta patología mental. A tal fin, hemos aplicado en nuestro trabajo un diseño de triadas para estimar la influencia de factores cognitivos y farmacológicos en la abstinencia de cocaína. Concretamente, como se detalla en la Sección de Material y Métodos se han estudiado simultáneamente tres tipos de animales: uno, que se autoadministra la droga "sabiendo" que puede obtenerla realizando un comportamiento (en nuestro caso apretar una palanca) y que, por tanto, regula su comportamiento de ingesta (sujeto CONTINGENTE); otro, emparejado con el anterior, que recibe la droga de forma pasiva porque el ordenador pone en marcha automáticamente la bomba de inyección cuando el animal que se autoadministra lo hace (sujeto NO CONTINGENTE), y un tercero, emparejado también con el Contingente que recibe suero salino (SALINO) cuando el Contingente se autoadministra cocaína. Este último sujeto hace de control experimental de 
los otros dos que se someten a los efectos farmacológicos de la cocaína. Este diseño nos permite tener una estimación de la influencia de las "expectativas" de los animales que pueden buscar y conseguir la droga, en contraposición a los que reciben la droga de forma pasiva y no tienen comportamiento de búsqueda.

\section{MATERIALY METODOS}

\section{ANIMALES}

Se utilizaron 72 ratas machos de la raza Lewis (Harlan Ibérica) que pesaban aproximadamente 300-350 gramos al principio del experimento. Ninguno de los animales habían sido expuestos previamente a ninguna situación experimental o drogas y se alojaron en las condiciones habituales de laboratorio con humedad y temperatura controladas $\left(23^{\circ} \mathrm{C}\right)$, ciclo luz-oscuridad (luz:08:00-20:00) y libre acceso a comida y bebida antes del inicio de los experimentos. Las instalaciones donde se mantuvieron los animales cumplen las Normas de la Unión Europea sobre Mantenimiento de Animales de Laboratorio.

\section{CIRUGÍA}

A los sujetos se les implantó un catéter en la vena yugular derecha a la altura de la aurícula derecha bajo anestesia de ketamina y diacepán. El catéter se extrajo subcutáneamente por la espalda del animal a la altura media escapular y se conectó a través de un muelle metálico (Alice King Chatman;USA), sujeto a la calota del animal, a la bomba dispensadora de droga. Todos los animales se alojaron en cajas individuales después de la operación y estuvieron al menos 7 días en recuperación.

\section{APARATOS}

Empleamos 12 cajas de condicionamiento operante (Coulburn Instruments; USA) para los estudios de autoadministración de cocaína. En cada caja se colocaron dos palancas situadas a ambos lados de una de las paredes de la caja y separadas por $14 \mathrm{~cm}$. Las palancas están diseñadas para registrar cada respuesta que se produzca cuando se apliquen al menos 3 gramos de fuerza sobre ellas. La dispensación de la droga o su vehículo( suero salino) se realizó gracias a una bomba automática (Harvard Instruments; USA) que operaba fuera de la caja del animal. El registro de los datos y el control de las cajas y del bomba se realizó mediante ordenadores IBM y una interfaz (Med Associates; USA).

\section{PROCEDIMIENTO EXPERIMENTAL}

\subsection{Autoadministración intravenosa de cocaína.}

Antes de la implantación del catéter, se entrenó a los animales para que aprendieran a apretar las palancas con bolitas de comida (Noyes Pellets;UK) como refuerzo, bajo un programa de reforzamiento de Razón Fija 5(RF5). Inicialmente, la presión de la palanca de la izquierda una sola vez (RF1) se traducía en la obtención de una bolita de comida $(45 \mathrm{mg}$ ) y el encendido de una lucecita por encima de la palanca. Después de que las respuestas bajo RF1 se mantuvieron,se aumentó gradualmente el número de presiones de palanca requeridos para la obtención de las bolitas de comida hasta llegar a RF5 y se inició un intervalo de 30 segundos (Tiempo Fuera de 30 s;TF30 s) después de la obtención de cada bolita. Cuando la conducta de presión de palanca reforzada con comida se mantuvo varios días con RF5, se procedió a la implantación del catéter como se describió antes. Tras el período post-operatorio, los 72 sujetos machos Lewis se asignaron al azar en triadas a cada uno de los tres siguientes grupos: a) Administración contigente (CONT) de cocaína (autoadministración) de 1 $\mathrm{mg} / \mathrm{kg} /$ inyección;b) Administración no contingente (NOCONT) de $1 \mathrm{mg} / \mathrm{kg} /$ inyección de cocaína o de c) Suero salino (SALINO) emparejados simultáneamente con la dispensación de cocaína en el sujeto que se autoadministraba. En un principio, la sustitución de comida por cocaína se empezó con un programa RF1 de reforzamiento y se incrementó progresivamente a RF5. En este programa, las respuestas dadas durante el intervalo TF30 s se registraron, pero no se traducían en inyecciones de cocaína. De igual modo, las presiones de la palanca derecha tampoco tenían consecuencias conductuales. Bajo el programa de reforzamiento RF5:TF30 s los animales se autoadministraron cocaína en sesiones de 2 horas diariamente durante un largo período de tiempo (de 4 a 6 semanas). Después de que se estableciera una conducta estable de autoadministración (menos de un 10\% de variación en el número de respuestas durante 3 días consecutivos) la droga se sustituyó por suero salino durante un mínimo de 5 días seguidos en las cajas de condicionamiento operante. Siguiendo a este primer período de extinción,la conducta de autoadministración de cocaína se adquirió y se mantuvo durante un período mínimo adicional de 2 semanas, si el criterio de conducta de autoadministración estable se había alcanzado. Posteriormente, la extinción con suero salino se hizo una segunda vez durante 0 (último día de autoadministración), 1, 5 y 10 días en las cajas de condicionamiento operante (tiempo en el los animales extinguieron completamente la conducta de autoadministración). En los días señalados de extinción y el día de la última sesión de autoadministración de cocaína, los sujetos se sacri- 
ficaron, se extrajeron sus cerebros y se mantuvieron a $-70^{\circ} \mathrm{C}$ para su posterior procesamiento por autorradiografía de receptores.

\subsection{Autorradiografía de los receptores de la familia D2 dopaminérgicos y del subtipo NMDA de los glutamatérgicos.}

Los cerebros de los animales se cortaron en secciones de 20 micras en un criostato (Reichert Jung; Modelo 2800 Frigocut N) a $-16{ }^{\circ} \mathrm{C}$, y se tomaron secciones representativas del Núcleo Accumbens de acuerdo con el atlas de Paxinos y Watson (1986). Marcamos los receptores de la familia de recptores D2 dopaminérgicos con un $1 \mathrm{nM}$ de 3H-YM 09951. Este radioligando tiene una $\mathrm{Kd}$ de $0.025 \mathrm{nM}$ para los D2, 0.014 nM para los D3, y 0.09 nM para los D4. En consecuencia, a la concentración de $1 \mathrm{nM}$ de $3 \mathrm{H}-\mathrm{YM}$ 09951, el 97\% de todos los receptores de la familia D2 quedan marcados. La unión al subtipo D2 se obtuvo incubando con 1nM de 3H-YM 09151, y añadiéndose al tampón de incubación $1 \mathrm{mM}$ de 7-OH-DPAT (para desplazar la unión al subtipo de receptores D3) y 500 nM de L745870 (para desplazar la unión al subtipo de receptores D4). La unión al subtipo D4 se obtuvo incubando con 1nM de 3H-YM 09151, y añadiéndose al tampón de incubación 800 nM de raclopride para desplazar los componentes D2 y D3. La unión a los receptores D3 se obtuvo por sustración entre la unión a los receptores D2 y D3. El tampón de incubación fué 50 $\mathrm{mM}$ Tris- $\mathrm{ClH}, 120 \mathrm{mM} \mathrm{CINa}, 5 \mathrm{mM} \mathrm{CIK}, 1,5 \mathrm{mM}$ $\mathrm{Cl} 2 \mathrm{Mg}$ y $4 \mathrm{mM} \mathrm{Cl2Ca}$. La unión no específica se evaluó por $10 \mathrm{mM}$ de (+)Butaclamol.

En el caso de los receptores de NMDA se cortaron también secciones de cerebro de $20 \mathrm{~mm}$ en el criostato al nivel del núcleo accumbens como se indicó más arriba. Estas secciones cerebrales se incubaron con 5 nM de 3H-MK 801. La unión no específica se evaluó mediante $100 \mathrm{mM}$ de MK-801.

Los portas se expusieron junto con patrones de radiactividad comercialmente disponibles (Amersham) a películas de $3 \mathrm{H}$-Hyperfilm( Amersham) durante 6 semanas. Las películas se revelaron con revelador Kodak D19 y se analizaron con un sistema de análisis de imagen computarizado.

\subsection{Análisis estadístico.}

Se definieron dos condiciones principales, Autoadministración y Extinción. En cada una de esas condiciones, los valores densitométricos, expresados en $\mathrm{nCi} / \mathrm{mg}$ de tejido equivalente, se analizaron mediante ANOVA con los factores Forma de Administración (CONT, NOCONT y SALINO) y Día de Extinción (0, 1 , 5 y 10). Las diferencias post-hoc se analizaron mediante la $\mathrm{t}$ de Student.

\section{RESULTADOS}

La Figura 1 muestra las fases de adquisición, mantenimiento, extinción y readquisición de la conducta de autoadministración de $1 \mathrm{mg} / \mathrm{Kg} /$ inyección de los animales del grupo de los CONTINGENTES. Como promedio, la ingesta total de cocaína durante las sesiones diarias de 2 horas fué de $11 \mathrm{mg} / \mathrm{kg}$ en las fases de mantenimiento. La cocaína mantuvo significativamente mayores frecuencias de autoadministración que el suero salino. Así, la frecuencia de autoadministración disminuyó rápidamente en las fases de extinción. Ello demuestra que la cocaína funcionaba como un reforzador positivo en nuestras condiciones experimentales.

\section{FIGURA 1}

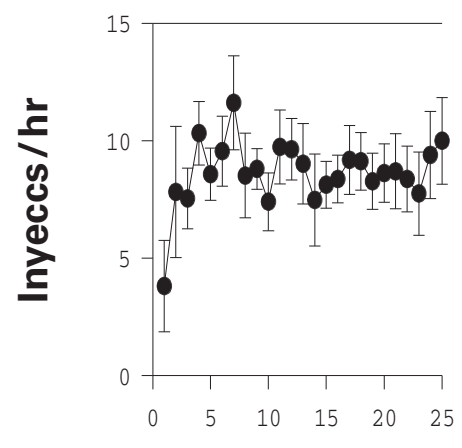

Adquisición

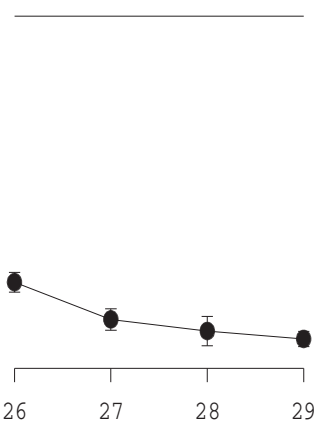

Extinción 1

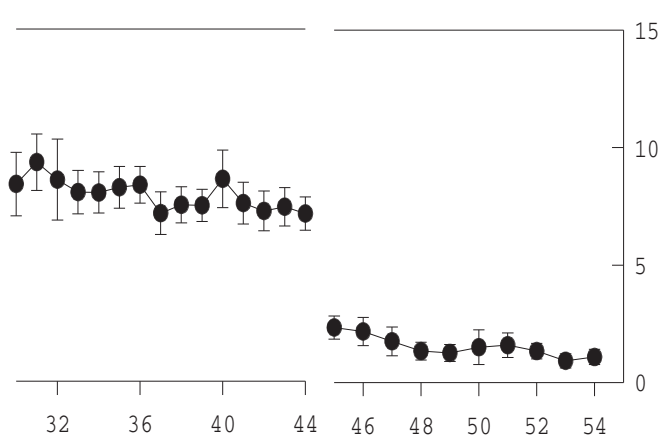

Readquisición

Extinción2 
En la Tabla I aparecen los valores densitométricos medios de la unión del subtipo D2 de dopamina en el núcleo accumbens, expresados en $\mathrm{nCi} / \mathrm{mg}$ de tejido equivalente, para cada una de las condiciones experimentales, de acuerdo con el diseño del experimento. En las Tablas II y III aparecen los resultados para los

\begin{tabular}{|c|c|c|c|}
\hline \multicolumn{4}{|c|}{$\begin{array}{l}\text { Tabla I. Unión específica del_H-YM } 09951 \text { a los } \\
\text { receptores D2 en el core del núcleo accumbens } \\
\text { de ratas durante la extinción de la conducta de } \\
\text { autoadministración de cocaína. Los valores están } \\
\text { expresados en nCi/mg de tejido equivalente. }\end{array}$} \\
\hline \multirow[b]{2}{*}{ Día 0} & Contingente & No Contingente & Salino \\
\hline & $a b 4,7$ & 7,55 & 8,99 \\
\hline Día 1 & $a b 4,9$ & 7,12 & 8,86 \\
\hline Día 5 & $a b 4,1$ & 6,1 & 8,91 \\
\hline Día 10 & a 6,1 & 6,2 & 8,96 \\
\hline \multicolumn{4}{|c|}{$\begin{array}{l}\text { a: estadísticamente significativamente menor que el } \\
\text { Grupo SALINO }(p<0.01) \\
\text { b: estadísticamente significativamente menor que el } \\
\text { Grupo NO-CONTINGENTE }(p<0.05)\end{array}$} \\
\hline
\end{tabular}

\begin{tabular}{|c|c|c|c|}
\hline \multicolumn{4}{|c|}{$\begin{array}{l}\text { Tabla II. Unión específica del__H-YM } 09951 \text { a los } \\
\text { receptores D3 en el core y shell del núcleo } \\
\text { accumbens de las ratas durante la extinción de la } \\
\text { conducta de autoadministración de cocaína. Los valores } \\
\text { están expresados en nCi/mg de tejido equivalente. }\end{array}$} \\
\hline & Contingente & No Contingente & Salino \\
\hline Día 0 & $\begin{array}{ll}5,36 & a b \\
4,79\end{array}$ & $\begin{array}{r}8,33 \\
7,45\end{array}$ & $\begin{array}{l}9,56 \\
9,80\end{array}$ \\
\hline Día 1 & $\begin{array}{ll}5,17 & a b \\
4,77\end{array}$ & $\begin{array}{l}8,92 \\
8,32\end{array}$ & $\begin{array}{l}9,82 \\
9,68\end{array}$ \\
\hline Día 5 & $\begin{array}{l}6,06 \\
5,54\end{array}$ & $\begin{array}{l}8,91 \\
8,84\end{array}$ & $\begin{array}{l}9,53 \\
9,46\end{array}$ \\
\hline Día 10 & $\begin{array}{l}6,83 \\
6,05\end{array}$ & $\begin{array}{l}7,26 \\
7,79\end{array}$ & $\begin{array}{l}9,69 \\
9,52\end{array}$ \\
\hline \multicolumn{4}{|c|}{$\begin{array}{l}\text { a: estadísticamente significativamente menor que el } \\
\text { Grupo SALINO ( }<<0.01) \\
\text { b: estadísticamente significativamente menor que el } \\
\text { Grupo NO-CONTINGENTE }(p<0.05)\end{array}$} \\
\hline
\end{tabular}

subtipos D3 y D4. y en la Tabla IV, los resultados para los receptores de NMDA. En todos los casos los valores densitométricos medios están expresados en $\mathrm{nCi} / \mathrm{mg}$ de tejido equivalente Las significaciones estadísticas halladas se describen en cada una de las Tablas.

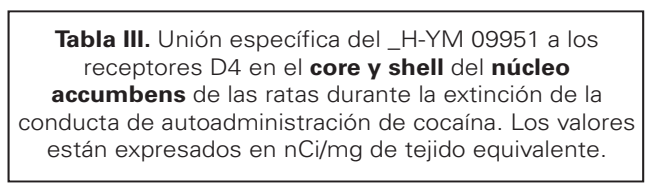

\begin{tabular}{|c|c|c|c|}
\hline & Contingente & No Contingente & Salino \\
\hline Día 0 & $\begin{array}{ll}1,86 & a b \\
2,01 & \end{array}$ & $\begin{array}{l}3,02 \\
2,93\end{array}$ & $\begin{array}{l}4,41 \\
4,08\end{array}$ \\
\hline Día 1 & $\begin{array}{ll}2,05 \\
1,70\end{array}$ & $\begin{array}{l}3,78 \\
3,44\end{array}$ & $\begin{array}{r}4,29 \\
4,10\end{array}$ \\
\hline Día 5 & $\begin{array}{ll} & \\
2,01 & \\
1,60 & \end{array}$ & $\begin{array}{l}3,69 \\
3,38\end{array}$ & $\begin{array}{l}4,11 \\
4,02\end{array}$ \\
\hline Día 10 & $\begin{array}{ll}1,95 \\
1,70\end{array}$ & $\begin{array}{l}2,45 \\
2,17\end{array}$ & $\begin{array}{l}4,45 \\
4,16\end{array}$ \\
\hline
\end{tabular}

a: estadísticamente significativamente menor que el Grupo SALINO $(p<0.01)$

b: estadísticamente significativamente menor que el Grupo NO-CONTINGENTE $(p<0.05)$

Tabla IV. Unión específica del_H-MK801 a los receptores de NMDA en el núcleo accumbens de las ratas durante la extinción de la conducta de autoadministración de cocaína. Los valores están expresados en nCi/mg de tejido equivalente.

\begin{tabular}{||c|r|c|c||}
\hline & Contingente & No Contingente & Salino \\
\hline Día 0 & $2,40 \mathrm{ab}$ & 2,82 & 3,03 \\
\hline Día 1 & $4,16 \mathrm{cb}$ & 3,11 & 3,29 \\
\hline Día 5 & $2,92 \mathrm{~b}$ & 3,28 & 3,52 \\
\hline Día 10 & 3,26 & 3,32 & 3,17 \\
\hline
\end{tabular}

a: estadísticamente significativamente menor que el Grupo SALINO $(p<0.01)$

$b$ : estadísticamente significativamente menor que el Grupo NO-CONTINGENTE $(p<0.05)$

c: estadísticamente significativamente mayor que el Grupo NO-CONTINGENTE $(p<0.05)$

$d$ : estadísticamente significativamente menor que el Grupo SALINO $(p<0.01)$ 
Las Figuras 2a-2b, 3a-3b y 4a-4b muestran autorradiogramas representativos de la unión total a los receptores D2, D4 y NMDA, respectivamente. En ellas puede apreciarse claramente la diferencia en la densidad de receptores de los distintos grupos experimentales durante el último día de autoadministración( DIA 0) y los días de extinción (DIAS 1, 5 Y 10). EI texto de las imágenes de los autorradiogramas está en inglés para poder sacar diaposivas de ellas y, en su caso, poder exponer estos resultados en Congresos, dado que obtener esas imágenes es costoso.
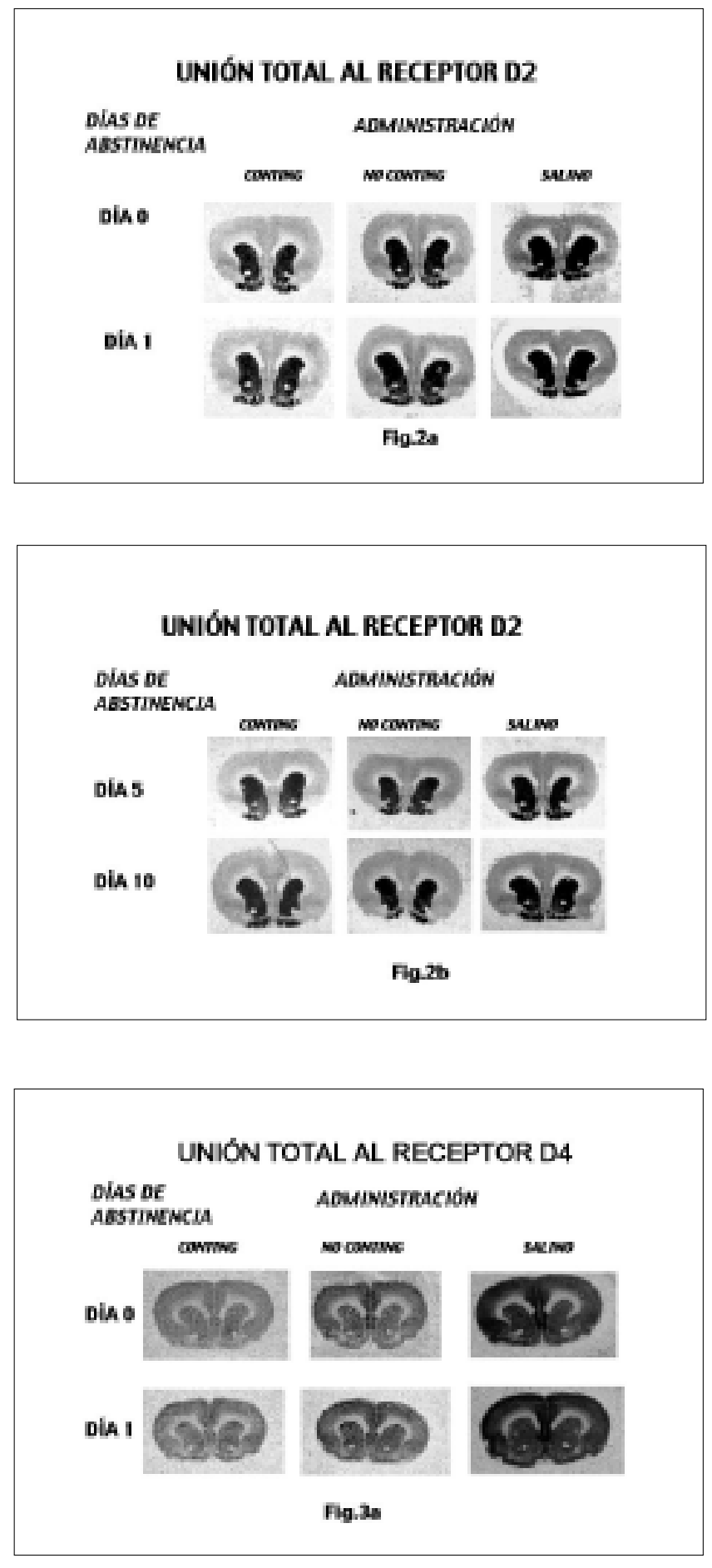

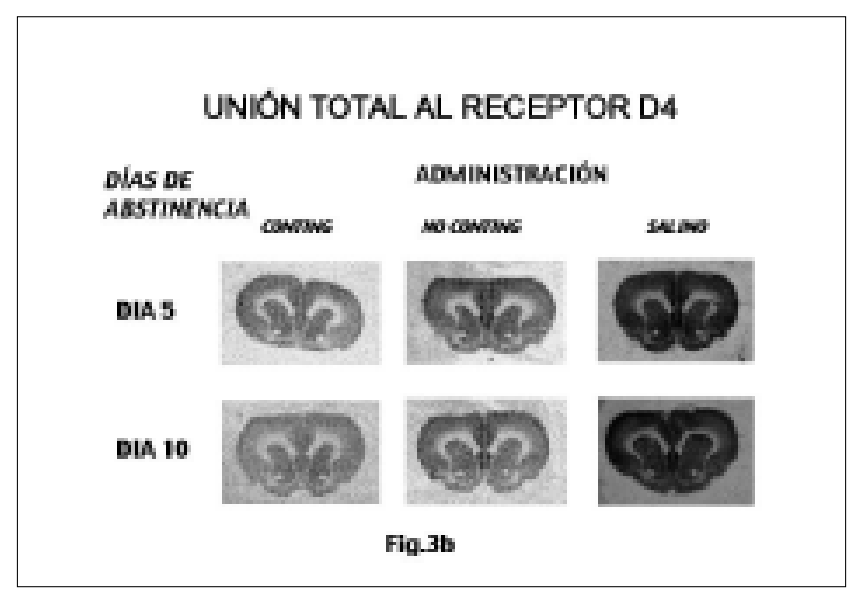

UNION TOTAL AL RECEPTOR DE NMDA
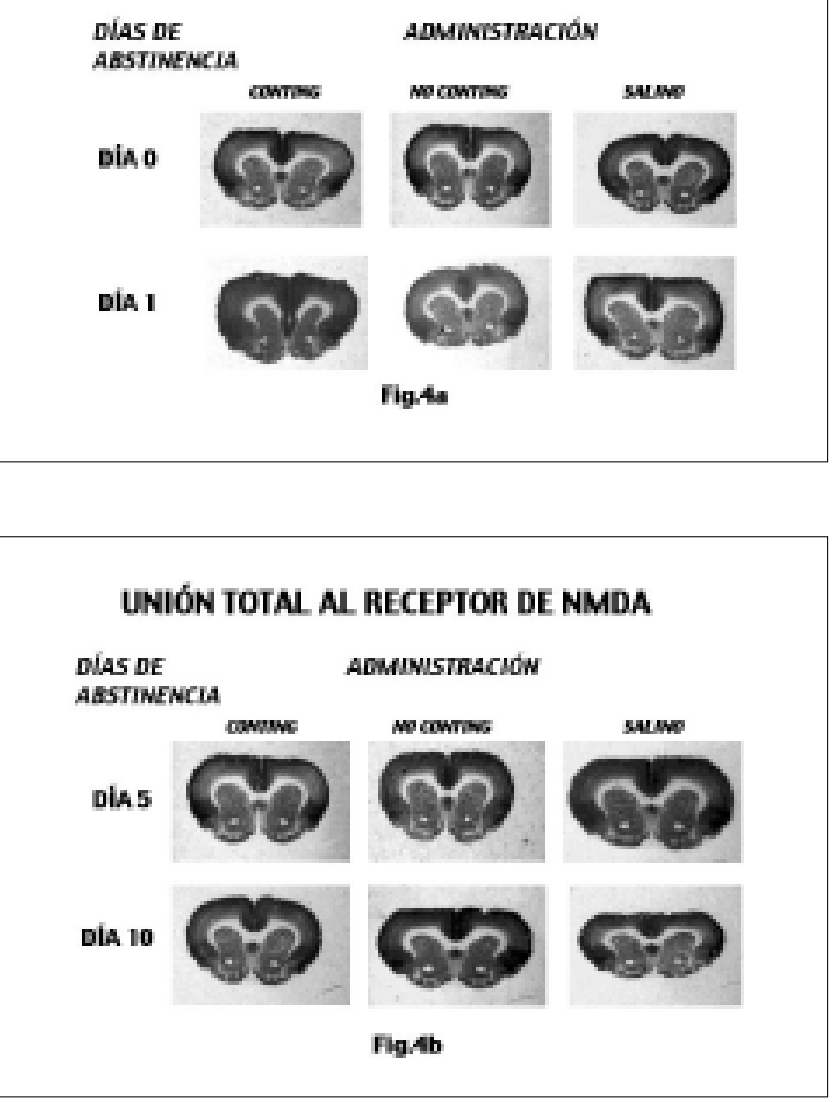

Considerando en conjunto los datos de los receptores de la familia D2 dopaminérgica, puede verse que hay una disminución significativa entre el último día de autoadministración (DIA 0 de extinción) y el resto de los días de retirada de cocaína en los grupos CONT y NOCONT, comparados con los de SALINO. La disminución es más acusada en el DIA 5 de extinción y hay una recuperación en el DIA 10. Además, puede comprobarse la importancia de la conducta de autoadministración (grupo CONT) frente a la administración pasiva de la droga (grupo NOCONT) en la reducción de la unión de los receptores D2 dopaminérgicos en 
el núcleo accumbens: la bajada en la unión es mucho mayor durante la extinción si el sujeto se ha autoadministrado la droga anteriormente que si la ha recibido pasivamente.

En lo que hace referencia a los receptores del subtipo NMDA glutamatérgico, en conjunto la unión a estos receptores es también menor en los sujetos que se han autoadministrado la droga, comparados con los de los grupos NOCONT y SALINO. Además, hay un aumento significativo en la unión a estos receptores el DIA 1 de extinción en el grupo de animales CONT comparados con Ios NOCONT y SALINO.

Tomados globalmente todos los resultados reflejan que durante la extinción de la autoadministración de cocaína se producen cambios neuroadaptativos en receptores de los sistemas dopaminérgico y glutamatérgico, siendo esos cambios más prominentes y duraderos en el sistema dopaminérgico.

\section{DISCUSIÓN}

Los resultados de este trabajo reflejan, en primer lugar, que existen cambios neuroadaptativos en la unión de los receptores de la familia D2 dopaminérgicos y en los glutamatérgicos del subtipo NMDA tras la extinción de la conducta de autoadministración de cocaína. Dichos cambios son más duraderos y mantenidos en el sistema dopaminérgico, lo cual sugiere que en los efectos de la abstinencia de cocaína a medio y largo plazo parecen participar más los elementos neurales del sistema dopaminérgico y no del glutamatérgico. No obstante, el sistema glutamatérgico puede ser importante en la fase de retirada temprana de cocaína, dado que solamente aparecen diferencias significativas a las 24 horas de abstinencia. En segundo lugar, los datos de este trabajo sugieren que factores cognitivos tales como "las expectativas" de los sujetos ante la posibilidad de conseguir la droga son importantes aspectos que deben considerarse, puesto que en aquellos animales que "saben" qué hacer para buscar y conseguir la droga (los del grupo Contingente), los cambios neuroadaptativos en la densidad de receptores dopaminérgicos y glutamatérgicos son más acusados y muestran claras diferencias respecto a los otros grupos. Los resultados obtenidos con los receptores glutamatérgicos en el primer día de abstinencia son especialmente interesantes, dada la importancia del sistema glutamatérgico en procesos de aprendizaje. Concretamente, dichos resultados sugieren que el ambiente estimular asociado a la administración contingente y no a otro tipo de autoadministración puede aumentar la unión a los receptores glutamatérgicos del subtipo NMDA. Es importante destacar a este respecto, dos aspectos: a) uno, que solamente en los animales que pueden regular su comportamiento de autoadministración se produce condicionamiento operante y b) otro, que un aumento de la unión a los receptores del subtipo NMDA refleja que hay mayor actividad glutamatérgica, dado que el ligando MK-801 o dizocilpina se une al canal de este receptor. Si hay más unión es indicativo de que hay más apertura del canal de glutamato, porque de otro modo no puede entrar el ligando a su sitio de unión. Por tanto, podemos sugerir que muy problamente hay un aumento de la transmisión glutamatérgica a las 24 horas de abstinencia de la cocaína, y que este efecto neuroquímico puede participar en la sintomatología de la fase temprana de la abstinencia.

Los datos obtenidos en el caso de los receptores de la familia D2 dopaminérgicos son bastantes consistentes a lo largo de los distintos días de extinción de nuestro estudio. Esto es, en general los cambios neuroadaptativos se mantienen hasta 10 días después de la ausencia de la droga. Del mismo modo, en todos los subtipos de la familia D2 dopaminérgica, los animales del grupo Contingente tienen una regulación a la baja de estos receptores más acusada. Como hemos comentado anteriormente, los cambios neuroadaptativos que aparecen en este grupo sugieren que hay factores cognitivos que pueden alterar la funcionalidad del sistema dopaminérgico a través de una mayor o menor densidad de sus receptores del núcleo accumbens.

Por otro lado, comparando nuestros datos con los de otros autores, nosotros encontramos un clara regulación a la baja de los receptores de la familia D2 dopaminérgica en los grupos de animales que han recibido cocaína. El procedimiento seguido por nosotros es muy distinto en dos aspectos fundamentales: uno, que empleamos la metodología de la autoadministarción intravenosa de drogas y otro, que nuestro tratamiento ha sido a muy largo plazo. Consideramos que estas dos diferencias fundamentales pueden ser relevantes en los hallazgos de este estudio. En todo caso, los resultados de nuestro estudio van en la línea de la opinión de algunos autores que afirman que el sistema dopaminérgico puede ser también un sustrato neurobiológico que participe en la sintomatología de la abstinencia de cocaína.

\section{CONCLUSIONES}

En conjunto, los resultados de este trabajo nos permiten sugerir las siguientes conclusiones:

1. La extinción de la conducta de autoadministración de cocaína durante los días 1, 5 y 10 que siguen al último de autoadministración de esta droga (DIA 0), produce una disminución de la unión a los receptores de la familia D2 de dopamina en el Núcleo accumbens, una región cerebral que parece implicada en las acciones reforzantes de las drogas de abuso. La dis- 
minución en la unión es más acusada en el DIA 5 de extinción y especialmente en los animales que se autoadministraron la cocaína, comparados con los que la recibieron pasivamente o recibieron suero salino. $A$ los 10 días de la extinción hay una recuperación en la densidad de estos receptores de modo que sus densidades se acercan a las que muestran los sujetos que no recibieron cocaína (los de grupo de SALINO).

2. En el caso de los receptores de glutamato del subtipo NMDA, la extinción de la conducta de autoadministración de cocaína a las 24 horas( DIA 1) desde el último de autoadministración (DIA 0), produjo un aumento de la unión en el grupo de animales recibió la droga de forma contingente. No se encontraron diferencias significativas en el resto de los días de extinción. Estos resultados indican que la posible influencia de los cambios neuroadaptativos en los receptores glutamatérgicos en la abstinencia de cocaína son más transitorios que los dopaminérgicos.

3. Los resultados obtenidos con los sujetos del grupo Contingente sugieren que los estímulos ambientales asociados con la autoadministración de cocaína pueden estar implicados en la regulación de los receptores de la familia D2 dopaminérgicos y de los glutamatérgicos durante la ausencia de cocaína, y apuntan a la importancia de la consideración de factores cognitivos en las neuroadpataciones promovidas por el consumo crónico de drogas.

4. Estos resultados sugieren que aquellos fármacos y/ o tratamientos que actúen sobre receptores de la familia D2 de dopamina, bien impidiendo o bien no produciendo una regulación a la baja de estos receptores, tienen potencialidad de ser útiles en la terapia de las recaídas en la adicción a la cocaína.

\section{BIBLIOGRAFÍA}

Carlezon, W.A. Jr., Kelz, M.B., Beretta, S., Benes, F.M., Neve, R.L., Nestler, E.J.(1999): Cocaine reward influenced by AMPA receptor composition in nucleus accumbens shell and basolateral amygdala. Soc. Neurosci. Abstr.,25 (1): 813 .

Chen, N.-H., and Reith, M.E.A. (1993). Dopamine and serotonine release-regulating autoreceptor sensitivity in A9/A10 cell body and terminal areas after withdrawal of rats from continuous infusion of cocaine. Journal of Pharmacology and Experimental Therapeutics, 267, 1445-1453.

Christie, M.J., Summers, R.J., Stephenson, J.A., Cook, C.J. and Beart, P.M.(1987): Excitatory amino acid projections to the nucleus accumbens septi in the rat: a retrogade transport study utilizing $\mathrm{D}-3 \mathrm{H}$-aspartate and 3H-GABA. Neuroscience, 22,425.

Cornish, J.L., Duffy, P., Kalivas, P.W.(1999): Nucleus accumbens glutamate transmission is involved in the reinstatement of cocaine-seeking behavior. 61th Annual
Scientific Meeting of the College on Problems of Drug Dependence (CPDD). Acapulco, México. pp. 27.

Fuller, T.A., Russchen, F.T. and Price, J.L. (1987): Sources of presumptive glutamatergic/aspartergic afferents to the rat ventral striatopallidal region. J. Comp.Neurol., 258, 317.

Gifford, A.N. and Johnson, K.M. (1992). Effect of chronic cocaine treatment on D2 receptor regulating the release of dopamine and acetylcholine in the nucleus accumbens and striatum. Pharmacology, Biochemistry and Behavior, 41, 841-846.

Goeders, N.E., and Kuhar, M.J. (1987). Chronic cocaine administration induces opposite changes in dopamine receptors in the striatum and nucleus accumbens. Alcohol and Drug Research, 7, 207-216.

Griffiths, R. R., Bigelow, G. E., Henningfield, J. E. (1980): Similarities in animal and human drug-taking behavior. In Advances in Substance Abuse. K. Mello (Ed.), Vol 1. JAI Press Inc., Greenwich CT., , 1-90.

Gulya, K., Grant, K.A., Valverius, P., Hoffman, P.L., Tabakoff, B. (1991): Brain regional specificity and time course of changes in the NMDA receptor-ionophore complex during ethanol withdrawal. Brain Res., 547, 129-134.

Henningfield, J. E.; Cohen, C.; Heisman, S. J.(1992). Quantitative comparison of drug self-administration in animals and humans. In Drug Dependence: From the molecular to the social behavior. J. Cohen-Yañez y cols., (Eds.). Elsevier Sci. Publ., 25-33.

Henry, D.J., and White, F.J. (1991). Repeated cocaine administration causes persistent enhancement of D1 dopamine receptor sensitivity within the rat nucleus accumbens. Journal of Pharmacology and Experimental Therapeutics, 258 (1), 882-890.

Kalivas, P.W. (1995): Interactions between dopamine and excitatory amino acids in behavioral sensitization to psychostimulants. Drug Alcohol Depend., 37, 95.

Kalivas, P.W., Sorg, B.and Hooks, M.S. (1993). The pharmacology and neural circuitry of sensitization to psychostimulants. Behav. Pharmacol., 4, 315.

Karler, R., Calder, L.D. and Turkanis, S.A. (1991).DNQX blockade of amphetamine behavioral sensitization. Brain Res.,552,295

Karler, R., Chandry, I.A., Calder, L.D. and Turkanis, S.A. (1990): Amphetamine behavioral sensitization and the excitatory amino acids. Brain Res., 537, 76

King, G.R., Ellinwood, E.H., Jr., Silva, C., Joyner, C.M., Xue, Z., Caron, M.G., and Lee, T.H. (1994). Withdrawal from continuous or intermittent cocaine administration: Changes in D2 receptor function. Journal of Pharmacology and Experimental Therapeutics, 269, 743-749.

Kleven, M.S., Perry, B.D., Woolverton, W.L. and Seiden, L.S. (1990): Effects of repeated injections of cocaine on D1 and D2 dopamine receptors. Brain Res., 532, 265-270.

Kunko, P.M., Ladenheim, B., Cadet, J.L., Carroll, F.I., and Izenwasser, S. (1997). Reductions in dopamine trans- 
porter and D1 receptor binding after chronic GBR 12909. NIDA Research Monograph, 178, 272.

Mayfield, R.D., Larson, G., and Zahniser, N.R. (1992). Cocaine-induced behavioral sensitization and D1 dopamine receptor function in rat nucleus accumbens and striatum. Brain Res., 573, 331-335.

Peris, J., Boyson, S.J., Cass, W.A., Curella, P., Dwoskin, L.P., Larson, G., Lin, L-H., Yasuda, R.P., and Zahniser, N.R. (1990). Persistence of neurochemical changes in dopamine systems after repeated cocaine administration. Journal of Pharmacology and Experimental Therapeutics, 253(1), 38-44.

Pierce, R.C., Bell, K., Duffy, P., Kalivas, P.W. (1996): Repeated cocaine augments excitatory amino acid transmission in the nucleus accumbens only in rats having developed behavioral sensitization. J. Neurosci., 16, 1550.

Ranaldi, R., French, E. and Roberts, D.C.S. (1996): Systemic pretreatment with MK-801(dizocilpine) increases breaking points for self-administration of cocaine on a progressive-ratio schedule in rats. Psychopharmacology, $128,83$.

Rocha, B.A., Fumagalli ,F., Gainetdinov, R.R., Jones, S.R.,
Ator, R., Giros, B., Miller, G.W., and Caron, M.G.(1998). Cocaine self-administration in dopamine-transporter knockout mice. Nature neuroscience 1(2),132-137.

Schenk, S., Valadez, A., McNamara, C., House, D.T. et al., (1993a). Development and expression of sensitization to cocaine's reinforcing properties: role of NMDA receptors. Psychopharmacology, 111, 332.

Schenk, S., Valadez, A., Worley, C.M. and McNamara (1993b): Blockade of the acquisition of cocaine selfadministration by the NMDA antagonist MK-801 (dizocilpine). Behav.Pharmacol., 4, 652.

Schmidt, E.F., Karanian, D.A., Schad, C.A., Neve, R.L., Self, D.W. (1999): Viral vector-mediated up-regulation of GluR1 AMPA/kainate receptor subunits in the nucleus accumbens reduces cocaine-seeking behavior during extinction. Soc. Neurosci. Abstr., 25 (1): 813.

Vorel, S.R., Hayes, R.J., Liu, X., Spector, J., Gardner, E.L.(1999): Neurotransmision through group 3 metabotropic glutanmate recptors inhibits reinstatement of cocaine- seeking behavior. Soc. Neurosci. Abstr., 25(1): 813.

Wolf, M.E. and Khansa, M.R. (1991): Repeated administration of MK-801 produces sensitization to its own locomotor stimulant effects but blocks sensitization to amphetamine. Brain Res., 562, 164. 